5. Phạm Mạnh Cường and Phạm Minh Thông, Đánh giá hiệu quả của phương pháp tạo hình đốt sống qua da trong điều trị xẹp đốt sống bệnh lý. Kỷ yêu các công trình nghiên cứu khoa học Bệnh viện Bach Mai, 2008. 1: p. 62-68.

6. Trinh Văn Cường and Nguyễn Quốc Bảo, Đăc điểm lâm sàng, cận lâm sàng và kết quả điều trị xẹp đốt sống do loãng xương bằng bơm cement sinh hoc qua cuống. Y Hoc Thành Phố Hồ Chí Minh, 2017. 21(6): p. 213-217.

7. Lee, J.-H., et al., Segmental deformity correction after balloon kyphoplasty in the osteoporotic vertebral compression fracture. Journal of Korean Neurosurgical Society, 2007. 42(5): p. 371.

\title{
VAI TRÒ CỦA CÁC CAN THIÊP ÍT XÂM LẤN TRONG ĐIỀU TRI BẢO TỒN KHÔNG MỔ CHẤN THƯƠNG THẬN
}

\author{
Ngô Trung Kiên' ${ }^{1}$ Hoàng Long ${ }^{2}$, Nguyễn Phú Việt ${ }^{3}$
}

TÓM TẮT

Mục tiêu: đánh giá vai trò của các biện pháp can thiệp ít xâm lấn trong điều trị bảo tồn không mổ chấn thương thân. Đối tượng và phương pháp: nghiên cứu tiến cứu các trướng hợp chấn thương thận được điều tri bảo tồn không mố tại bênh viên Việt Đức từ năm 2013 đến 2018. Kết quả: 24 bệnh nhân can thiệp mạch, trong đó 13 trường hợp được chỉ định từ đâu do có tổn thương mach máu thân biểu hiên chảy máu thể hoạt động, 11 bệnh nhân được chỉ định trong quá trình theo dỗi điều trị do giả phình động mạch thận. 13 trường hợp nội soi tiết niệu đặt thông jj, trong đó 8 trường hợp chỉ định từ đầu, 5 trường hợp chỉ định trong quá trình theo dõi điêuu trị do thoát nước tiểu dai dằng hoặc máu cục trong bể thận. Kết luâan: các biện pháp can thiêp ít xâm lấn xử lý được các tổn thương trong chấn thương thận mà trước đẩy thường phải phẫu thuât, do đó làn tăng tỷ lệ thành công của điều trị bảo tồn không mổ.

Tư khóa: chấn thương thận, can thiệp mach, nội soi tiết niệu.

\section{SUMMARY}

\section{THE ROLE OF MINI INVASIVE}

\section{INTERVENTION IN NON OPERATIVE}

MANAGEMENT IN RENAL TRAUMA

Objectives: to evaluate the role of less invasive interventions in conservative treatment without renal trauma surgery. Subjects and methods: a prospective study of non-operative management renal trauma cases at Viet Duc Hospital from 2013 to 2018. Results: 24 patients with vascular interventions, of which 13 were initially indicated due to renal vascular lesions that expressed active bleeding, 11 were assigned during follow-up treatment because of renal artery aneurysm. 13 cases of urological endoscopy, in which 8 cases indicated from the beginning, 5 cases

${ }^{1}$ Bênh viên Xanh Pôn

${ }^{2}$ Đại học Y Hà Nội

${ }^{3}$ Học viện Quân Y

Chịu trách nhiệm chính: Ngô Trung Kiên

Email: kienngotrung.knt@gmail

Ngày nhận bài: 17.12.2020

Ngày phản biên khoa họ: 26.01.2021

Ngày duyệt bài: 3.2.2021 indicated during treatment monitoring due to persistent urinary extravasation or blood clots in the renal pelvis. Conclusion: Less invasive interventions address lesions in renal trauma that used to be surgical, thus increasing the success rate of nonoperative management.

Keywords; renal trauma, vascular intervention, urinary endoscopy.

\section{I. ĐĂT VẤN ĐỀ}

Chấn thương thận hay gặp nhất trong chấn thương đường tiết niệu, chiếm tỷ lệ khoảng $10 \%$ chấn thương bụng kín và khoảng 1-5\% các chấn thương nói chung. Nguyên nhân chủ yếu là tai nạn giao thông chiếm tới 65,5\% - 87,5\%[1].

Trước đây, CTT chủ yếu được chỉ định mổ cấp cứu giống như chấn thương các tạng đặc khác nhưng tỷ lệ phải cắt bỏ thận rất cao, có thể có những biến chứng, di chứng hoăc đôi khi là một can thiệp không cân thiết vì tổn thương đã tự cầm máu.

Trong khoảng 3 thập kỷ trở lại đây, nhờ sự phát triển của chẩn đoán hình ảnh, đặc biệt là chụp cắt lớp vi tính đa dãy (MSCT - multi slide computed tomography) $)_{\ell}$ việc đánh giá và phân loại thương tổn giải phâuu trong CTT được chính xác hơn, tạo cơ sở để quyết định các phương pháp điều trị thích hợp. Bên cạnh đó, những tiến bộ của y học trong nhiêuu lĩnh vực được áp dụng trong quá trình điều trị, theo dõi và xử trí các biến chứng của CTT đã làm cho tỷ lệ thành công của điều trị bảo tôn không mổ tăng lên. Đó là điện quang can thiệp (Interventional Radiology), nút mạch chọn lọc với các trường hợp CTT chảy máu nhiêu từ nhánh động mạch bị tổn thương hoặc nút giả phình mạch hình thành sau CTT. Với các khối máu tụ, nước tiểu, có thể dẫn lưu qua da kết hợp với đặt thông jj niệu quản - bể thận qua nội soi tiết niệu (Endourological) [5].

Việc áp dụng MSCT và các biện pháp can thiệp ít xâm lấn trong chẩn đoán và điêu trị chấn thương thân đã làm cho phương pháp điều trị bảo tồn không mổ (NOM) trở thành lựa chọn 
hàng đầu và có thể chỉ định cho cả các trường hợp CTT nặng độ IV, $V$ có tình trạng lâm sàng ổn định. Chúng tôi tiến hành nghiên cứu này nhằm đánh giá vai trò của các biên pháp can thiệp ít xâm lấn trong điều trị bảo tồn không mổ chẩn thương thận.

\section{II. ĐỐI TƯợNG VÀ PHƯƠNG PHÁP NGHIÊN CỨU}

Gồm những bệnh nhân chấn thương thận được chẩn đoán và điều trị bảo tồn không mổ tại Bệnh viện Việt Đức từ tháng 10 năm 2013 đến tháng 12 năm 2018. Điều trị bảo tồn không mổ (Non operative management: NOM) ở đây bao gồm điều trị nội khoa đơn thuần, can thiệp mạch và nội soi tiết niệu.

\section{* Tiêu chuẩn lựa chọn:}

- Bệnh nhân được chẩn đoán CTT từ độ I đến độ $\mathrm{V}$, được đánh giá mức độ tổn thương thận bẳng chụp MSCT và được điều trị bảo tồn không mổ tại Bệnh viện Việt Đức.

- Tất cả các lứa tuổi, nam và nữ.

- Tình trạng huyết động ổn định từ đầu hoặc có sốc nhưng đáp ứng sau hồi sức.

- Bao gồm cả CTT đơn thuần và CTT phối hợp với chấn thương bụng hoặc các chấn thương khác nhưng không phải phẫu thuật CTT.

\section{*Tiêu chuẩn loại trừ:}

- Chấn thương thận mổ cấp cứu trong 24 giờ đầu hoặc đã được mổ ở tuyến trước.

- Các tổn thương thận do vết thương hoặc do can thiệp thủ thuật điều trị gây nên.

- Những bệnh nhân CTT không được chụp MSCT.

* Phương pháp nghiên cứu

- Nghiên cứu theo phương pháp tiến cứu mô tả, có phân tích lâm sàng, theo dõi dọc không có đối chứng.

- Thu thập thông tin theo mẫu bệnh án chung dựa trên các đặc điểm lâm sàng, cận lâm sàng và chẩn đoán hình ảnh, chỉ định điêu trị bảo tồn không mổ $\mathrm{CTT}$, diễn biến trong quá trình theo dõi điều trị, các biến chứng và phương pháp xử trí các biến chứng.

*Cõ mẫu nghiên cứu. Cõ̃ mẫu nghiên cứu được tính theo công thức độ tin cậy tương đối cho một tỷ lệ của nghiên cứu mô tả cắt ngang như sau:

$$
n=Z_{1-\alpha / 2}^{2} \frac{1-p}{\varepsilon^{2} p}
$$

Trong đó: n là số bệnh nhân cần cho nghiên cứu.

$Z_{1-\alpha / 2}=1,96$ (tra theo bảng ứng với mức độ tin cậy $95 \%$ ).

$\mathrm{p}=0,9$ được lấy theo tỷ lệ điều trị bảo tồn không mổ CTT thành công của một số nghiên cứu đã được công bố $\varepsilon=$ Độ chính xác tương đối được lấy bằng $0,07(7 \%)$.

Thay vào công thức trên, số bệnh nhân tối thiểu cần cho nghiên cứu là 90

Xử lý số liệu: Các số liệu thu thập được đưa vào mẫu nghiên cứu của từng bệnh nhân và xử lý theo chương trình thống kê SPSS 15.0

\section{KẾT QUẢ NGHIÊN CỨU}

Từ tháng 10 năm 2013 đến tháng 12 năm 2018, có 90 trường hợp bệnh nhân CTT được điều trị bảo tồn tại bệnh viện Việt Đức. Trong đó có 24 trường hợp can thiệp mạch và 13 trường hợp nội soi đặt thông jj.

*Tuổi và giới:Tuổi trung bình của nhóm nghiên cứu là $35 \pm 16,4$. Tuổi lớn nhất là 81 , tuổi nhỏ nhất là 8

*Chỉ định can thiệp mạch trong điêuu trị bảo tồn CTT

Bảng 3.1: Các tổn thương trên MSCT được xác định trên DSA $(n=24)$

\begin{tabular}{|c|c|c|}
\hline $\begin{array}{c}\text { Dấu hiệu } \\
\text { trên MSCT }\end{array}$ & $\begin{array}{c}\text { Tốn thương } \\
\text { mạch máu } \\
\text { trên DSA }\end{array}$ & $\begin{array}{c}\text { Đố } \\
\text { chính } \\
\text { xác }\end{array}$ \\
\hline Chảy máu thể hoạt động & 13 & $100 \%$ \\
\hline Giả phình động mạch & 9 & $100 \%$ \\
\hline Thông động tĩnh mạch & 2 & $100 \%$ \\
\hline
\end{tabular}

Số BN được can thiệp mach do chảy máu thể hoạt động ảnh hưởng đến huyết động là nhiều nhất với $13 \mathrm{BN}$

Bảng 3.2: Chi định can thiệp mạch với chảy máu thể hoạt động ( $n=13$ )

\begin{tabular}{|c|c|c|}
\hline Độ chấn thương & Số BN & $\mathbf{\%}$ \\
\hline CTT độ II & 1 & 7,7 \\
\hline CTT độ III & 4 & 30,8 \\
\hline CTT độ IV & 8 & 61,5 \\
\hline Tống & $\mathbf{1 3}$ & $\mathbf{1 0 0 , 0}$ \\
\hline
\end{tabular}

Bảng 3.3: Chỉ định can thiệp mạch với các tổn thương mạch máu phát hiện trong quá trinh theo dối

\begin{tabular}{|c|c|c|c|c|}
\hline \multirow{2}{*}{ Độ CT } & \multicolumn{4}{|c|}{ Tốn thương } \\
\cline { 2 - 5 } & Giả phình ĐM & \multicolumn{2}{|c|}{ Thông ĐTM } \\
\cline { 2 - 5 } & Số BN & Tỷ lệ \% & Số BN & Tỷ lệ \% \\
\hline Độ II & 1 & 11,1 & & \\
\hline Độ̀ III & 3 & 33,3 & 1 & 50 \\
\hline Độ IV & 4 & 44,4 & 1 & 50 \\
\hline Độ̉ V & 1 & 11,1 & & \\
\hline Tồng & 9 & 100 & 2 & 100 \\
\hline
\end{tabular}

*Kết quả nút mạch

- Tỷ lệ thực hiện kỹ thuật nút mạch thành công là $100 \%$.

- Tỷ lệ bệnh nhân hết đái máu sau nút mạch là $100 \%$.

- Có 3 bệnh nhân phải chuyển mổ. Trong đó, 
2 bênh nhân mổ nội soi lấy khối máu tụ quanh thận do khối máu tụ quanh thận kích thước lớn và 1 bệnh nhân chấn thương thân độ $V$ tiến triển thành áp xe quanh thận phải mổ mở cắt thận.

\section{*Chỉ định nội soi đăt thông JJ}

Bảng 3.4. Thời điểm chỉ định nội soi đặt thông J J

\begin{tabular}{|c|c|c|}
\hline Thời điếm & Số $\mathbf{B N}$ & Tỷ lệ \% \\
\hline Chỉ định từ đầu & 8 & 61,5 \\
\hline $\begin{array}{c}\text { Chì định trong thời } \\
\text { gian theo dôi }\end{array}$ & 5 & 38,5 \\
\hline Tống & $\mathbf{1 3}$ & $\mathbf{1 0 0 , 0}$ \\
\hline
\end{tabular}

Trong quá trình theo dõi điều trị, chỉ định đặt thông JJ bổ sung 5 trường hợp.

* Kết quả nội soi đặt thồng JJ

Bảng 3.5. Kêt quả nội soi đặt jj

\begin{tabular}{|c|c|c|}
\hline Kết quả & Số BN & Tỷ lệ $\%$ \\
\hline Thành công & 11 & 84,6 \\
\hline Chuyến mố & 2 & 15,4 \\
\hline Tống & $\mathbf{1 3}$ & $\mathbf{1 0 0 . 0}$ \\
\hline
\end{tabular}

Trong tống số 13 ca đặt thông Jj, phần lớn là thành công, nhưng vẫn có $15,4 \%$ bệnh nhân phải chuyển mổ, trong đó $1 \mathrm{ca}$ mổ nội soi lấy máu cục, 1 ca mổ mở cắt thận.

\section{BÀN LUẬN}

Điều trị bảo tồn không mổ hiện nay là xu hướng chung trong điều trị chấn thương thận. Lựa chọn phương pháp tốt nhất để nâng cao chất lượng điều trị phụ thuộc vào nhiều yếu tố. Trong đó, phân loại chính xác tổn thương thận bằng chẩn đoán hình ảnh đóng vai trò quan trọng. Thêm vào đó, sử dụng các biện pháp can thiệp ít xâm lấn, thường áp dụng là can thiệp mạch và nội soi tiết niệu đặt thông jj, đã làm tăng tỷ lệ thành công trong điều trị bảo tồn không mố chấn thương thân. Từ tháng 10 năm 2013 đến tháng 12 năm 2018, đã có 90 bệnh nhân chấn thương thân được điều trị bảo tồn không mổ tại bệnh viện Việt Đức. Trong đó, 13 bệnh nhân có dấu hiệu chảy máu thể hoạt động, 8 bệnh nhân tổn thương đường bài tiết được chỉ định áp dụng ngay các can thiệp ít xâm lấn ngay trong 24 h đâu là can thiệp mạch và nội soi tiết niệu đặt thông jj. Trong quá trình theo dõi điều trị, có thêm lần lượt $11 \mathrm{BN}$ và $5 \mathrm{BN}$ được chỉ định can thiệp mạch và nội soi tiết niệu do tổn thương chảy máu thứ phát và tổn thương đường bài tiết không tự liền.

Can thiệp nút mạch thận trong chảy máu do thương tổn động mạch thận là kỹ thuật nhằm gây tắc chọn lọc hoặc siêu chọn lọc nhánh động mạch thận bị tổn thương. Trong khoảng 3 thập kỷ gần đây, với sự ra đời của các phương tiện chẩn đoán hình ảnh hiện đại và kỹ thuật ngày càng hoàn thiện, phương pháp can thiệp mạch đã giúp điều trị hiệu quả đa số các trường hợp chảy máu do thương tổn mach máu thân. Một số báo cáo như Fisher RD (1989), Miller D.C (2002) cho rằng phương pháp nút mạch thận chọn lọc tỏ ra khá an toàn và hiệu quả trong việc kiểm soát chảy máu do tổn thương động mạch thận [4] [6]. Một nghiên cứu của Ramaswamy RS và CS (2016) cho thấy nút mạch chọn lọc giúp giảm tỉ lệ cắt thận lên đến $78 \%$ và $83 \%$ ở chấn thương thận độ IV và độ V [9]

Kể từ trường hợp can thiêp mach điều trị chảy máu động mạch thận thành công đầu tiên được thông báo năm 1973 [4], phương pháp điện quang can thiệp này đã được phát triển và áp dụng để điều trị cho các tổn thương động mạch thận do nhiều nguyên nhân khác nhau trong đó có chấn thương thận. Đây là phương pháp vừa chẩn đoán, vừa điều trị. Các thương tổn mạch máu thường gặp trong chấn thương thận là chảy máu thể hoạt động (hình ảnh trên MSCT là thoát thuốc cản quang thì sớm), giả phình động mạch và thông động tĩnh mạch thận hình thành sau chấn thương.

Giả phình động mạch thận hình thành do tất cả các lớp của thành mạch bị tổn thương, mô xung quanh tạo ra một lực chèn ép làm quá trình chảy máu chẩm lại và tạo ra một khối máu tụ quanh chỗ động mạch bị tổn thương, phản ứng xơ hoá bao bọc khối máu tụ tạo nên một cấu trúc gần giống với túi phình động mạch. Sau đó, khối máu tụ bị ly giải và xuất hiện dòng máu chảy qua làm cho túi giả phình bị nở to dẩn đến võ̃ túi gây chảy máu. Theo Ngo (2010) [7], giả phình động mạch là thương tổn quan trọng bởi vì một vết rách thành động mạch chỉ được bít tạm thời bởi khối máu tụ và mô liên kết xung quanh có thể chuyển biến gây chảy máu do có sư gia tăng áp suất thủy tînh trong lòng mach dẫn đến mất cân bằng áp lực với hiệu ứng chèn ép của khối máu tụ và mô liên kết xung quanh. Trần Ngọc Sinh (2011) [2] cũng cho rẳng chảy máu thứ phát ở bệnh nhân CTT có thể gặp khoảng 2- 3\% các bênh nhân được điều trị nội khoa bảo tồn, sau một chấn động nhe hoặc gắng sức, bệnh nhân thấy đau chói bên chấn thương, xuất hiên đái máu và khối máu tụ to ra. Qua đó cho thẩy, cần thân trọng theo dõi và xử trí sớm những trường hợp CTT có thương tổn giả phình động mạch.

Kết quả trong nghiên cứu cho thấy khả năng bảo tồn chức năng thân của can thiêp mach rất khả quan, nút mạch chọn lọc hoặc siêu chọn lọc 
có thể bảo tồn tối đa nhu mô thận. Chatziioannou (2004) nghiên cứu đánh giá khả năng bảo tồn nhu mô và chức năng thận sau khi can thiệp nút mạch thận chọn lọc các trường hợp tổn thương động mạch thận ghi nhận tỷ lệ bảo tồn nhu mô thận đạt $83,33 \%$, vùng thận bị nhồi máu chỉ từ 0 - 15\%. Trước đây, khi chưa áp dụng phương pháp can thiệp mạch trong xử trí các trường hợp tổn thương động mạch thận do chấn thương thì nguy cơ phấu thuật cắt bỏ thận khá cao nếu bệnh nhân có chỉ định phẫu thuật để kiểm soát chảy máu. Phẫu thuật để kiểm soát chảy máu trong chấn thương thận thường được cân nhắc khi điều trị nội khoa bảo tồn thất bại, tuy nhiên phương pháp này thường dẫn tới phẫu thuật cắt thận hơn là bảo tồn thận. Một số nghiên cứu trong nước cho thấy, phẫu thuật để kiểm soát chảy máu trong điều trị chấn thương thận có tỷ lệ cắt thận khá cao. Theo Vũ Nguyễn Khải $\mathrm{Ca}(2000)$ [1] ghi nhận tỷ lệ này lên đến $67,39 \%$ (62/92 trường hợp). Với sự phát triển của các phương tiện chẩn đoán hình ảnh và các kỹ thuật ít xâm hại, ngày nay điều trị can thiệp tối thiểu mà điển hình là nút mach chọn loc điểu trị tổn thương động mạch thận đã trở thành tiêu chuẩn trong tiếp cận điều trị. Theo Phillips $B$ (2017), các phương thức điêu trị bảo tồn không mổ CTT (gồm nội khoa và can thiệp nội mạch) đang có xu hướng chiếm ưu thế so với phương pháp phẫu thuật với tỉ lệ là $63 \%$ và $37 \%$, [8]. Do đó, xu hướng trong điều trị chấn thương thận hiện nay, kể cả chấn thương thận mức độ nặng có tình trạng huyết động ổn định là điều trị bảo tồn không mổ, áp dụng những phương pháp ít xâm hại để hạn chế tối đa chỉ định phẫu thuật.

Nghiên cứu của chúng tôi có 24 trường hợp thương tổn mạch máu thận, trong đó 13 trường hợp tổn thương chảy máu thể hoạt động và 11 trường hợp tốn thương mạch máu thận phát hiện trong quá trình theo dõi điều trị nội khoa đơn thuân gồm có 9 trường hợp giả phình động mạch thận và 2 trường hợp thông động tĩnh mạch thận. Bảng 3.2 cho thấy can thiệp mạch với chảy máu thể hoạt động được chỉ định đối với 13 trường hợp, với các mức độ chấn thương thận độ từ II tới IV, tương ứng từ 7,7 tới $61,5 \%$. Theo bảng 3.3, trong quá trình theo dõi các bệnh nhân điều trị nội khoa đơn thuần, nghiên cứu phát hiện 9 ca giả phình động mạch với độ chấn thương thận từ II tới IV và 2 ca thông động tĩnh mạch ở chấn thương thận độ III và IV. Các tổn thương mạch thận được phát hiện trên MSCT đều được chụp mạch lại trên DSA trước khi tiến hành nút mạch và tất cả các trường hợp chụp mạch đều cho thấy các hình ảnh tổn thương mạch máu thận được phát hiện trên MSCT là chính xác. Điều này cho thấy giá trị của MSCT trong chẩn đoán tổn thương mạch máu thận nói riêng và các tổn thương khác trong chấn thương thận nói chung.

Một can thiệp ít xâm lấn hay được áp dụng trong điều trị khác là nội soi tiết niệu đặt thông jj. Các tổn thương võ̃ thận lan vào đường bài tiết hoặc rách đoạn nối bể thận niệu quản được chỉ đinh nội soi tiết niệu đặt thông jj với mục đích dẫn lưu thật tốt nước tiểu qua đường tự nhiên, khối tụ dịch nước tiểu sẽ giảm dần và những tổn thương đường bài tiết vì thế có thể tự liền được.

Thoát nước tiểu do tổn thương hệ thống đường bài tiết có thể gặp trong khoảng $30 \%$ các trường hợp chấn thương thận mức độ nặng (III V) và khoảng $51 \%$ với chẩn thương thận độ IV và $V$. Nếu chỉ tính riêng chấn thương thận độ IV, tỷ lệ thoát nước tiểu do tổn thương hệ thống đường bài tiết có thể lên tới 74\%. Khoảng 29\% trong số này cần đặt stent niệu quản [3].

Hơn $80 \%$ tổn thương hệ thống đường bài tiết không liên quan tới bể thận hay niệu quản có thể tự lành. Thoát nước tiểu dai dẳng có thể được xử trí can thiệp xâm lấn tối thiểu bằng nội soi tiết niệu đặt thổng jj hoặc dẫn lưu thận qua da khi đặt stent niệu quản thất bại. Cả hai biện pháp đều có thể thực hiện được với giảm đau nhẹ. Các chỉ định khác cho nội soi tiết niệu đặt thông jj gồm đau dai dẳng, có cục máu đông ở bể thận, ứ nước thận hoặc có hẹp đoạn nối bể thận niệu quản từ trước.

Thoát nước tiểu dai dẳng có thể dẫn đễn biến chứng tạo thành các khối tụ nước tiểu. Các khối tụ nước tiểu này có thể được xử trí dẫn lưu qua da bằng catheter. Dẫn lưu được chỉ định khi khối tụ nước tiểu kích thước lớn hoặc nhiễm trùng, sốt, rò nước tiểu hoặc đau tăng.

Trong nghiên cứu có 8 bệnh nhân được chỉ định nội soi tiết niệu đặt thông jj từ đầu do các bệnh nhân có đường vỡ thận sâu lan tới đường bài tiết. Trên lâm sàng bệnh nhân đau vùng thắt lưng nhiều, bụng chướng nhiều do kích thích sau phúc mạc. 5 trường hợp được chỉ định nội soi tiết niệu trong quá trình điểu trị cũng là các trường hợp chấn thương thận độ IV có thoát nước tiểu dai dẳng và máu cục nhiều trong bể thận. Các bệnh nhân sau đặt thông jj đều có cải thiện tốt trên lâm sàng, đỡ đau vùng thắt lưng, bụng đỡ chướng. Điều đó cho thấy khi nước tiểu được dẫn lưu tốt sẽ làm giảm sự thoát nước tiểu qua tổn thương đường bài tiết ra khoang sau phúc mạc, làm giảm áp lực lên tổn thương và do 
đó làm cho quá trình lành vết thương được thuận lợi hơn.

\section{KẾT LUÂ̂N}

Bảo tồn không mổ là lựa chọn hàng đâu trong điều trị chấn thương thận hiện nay. Các biện pháp can thiệp ít xâm lấn như can thiệp mạch và nội soi tiết niệu có thể xử lý được các thương tổn mạch máu và đường bài tiết được phát hiện ngay từ đâu hoặc xuất hiện trong quá trình theo dõi điêuu trị, các thương tổn mà trước đây thường được chỉ định phẫu thuật. Chính vì vậy, việc áp dụng các can thiệp ít xâm lấn đã làm tăng tỷ lệ thành công của điều trị bảo tôn không mổ chấn thương thận.

\section{TÀI LIÊU THAM KHẢO}

1. Vũ Nguyễn Khải Ca (2001). Nghiên cứu chẩn đoán và điều trị phẫu thuật chấn thương thận, Luận văn Thạc sĩ Y học, Đại học Y Hà Nội, Hà Nội, $53-57$.

2. Trân Văn Sána, Trân Naoc Sinh (2011), Chấn thươna thân và vết thươna thân. Bài Giảna Bênh học niệu khoa, Nhà xuất bản Phương Đông, 9-48.

3. Bruce L.M., Croce M.A., Santaniello J.M., et al
(2001), Blunt renal artery injury: incidence, diagnosis and management, The American Journal of Surgery, 67: 550-554.

4. Fisher R.G., Ben-Menachem Y., Whigham C. (1989), Stab wounds of the renal artery branches: angiographic diagnosis and treatment by embolization, AJR Am J Roentgenol, 152 (6): 1231-5.

5. Keihani S., Anderson R.E., Fiander M., et al. (2018). Incidence of urinary extravasation and rate of ureteral stentina after hiah-arade renal trauma in adults: a meta-analvsis. Transl Androl Urol. $\quad 7$ (Suppl 2): $\quad$ S169-S178. doi:10.21037/tau.2018.04.13.

6. Miller D.C., Forauer A., Faerber G.J. (2002), Successful angioembolization of renal artery pseudoaneurysms after blunt abdominal trauma, Uroloqv, 59(3): 444.

7. Nao T.C., Lee J.J., Gonzalao M.L. (2010), Renal Dseudoaneurvsm: an overview. Nat Rev Urol. 7(11): 619-625.

8. Phillips B.J., Mirzaie M., Holzmer S., et al (2017), Penetrating Renal Trauma: A Review of Modern Management, J Eme Med Int Care, 3(3): 121.

9. Ramaswamy R.S., Darcy M.D (2016), Rterial Embolization for the Treatment of Renal Masses and Traumatic Renal Injuries, Tech Vasc Interv Radiol, 19: 203-10.

\section{ĐĂC ĐIỂM HÌNH ẢNH CỦA 99MTc-MAA SPECT/CT TRONG LÂP KẾ HOẠCH ĐIỀU TRI UNG THƯ GAN BẰNG HẠT VI CẦU GẮN YTTRIUM-90 Ở BỆNH NHÂN UNG THƯ GAN NGUYÊN PHÁT}

\section{TÓM TẮT}

Tổng quan: 99mTc-MAA SPECT/CT được sử dụng để đánh giá sư phân bố của hat vi câu và ước tính liều hấp thu tại khối $u$. Hơn nữa, cho đến nay, đặc điểm hình ảnh của 99mTc-MAA SPECT/CT vẫn chửa đước đánh giá một cách đầy đủ. Do vậy, chúng tôi tiển hành nghiên cứu nhằm đánh khác sự khác biệt giữa hình ảnh ${ }^{99 m T C-M A A ~ S P E C T / C T ~ s o ~ v o ̛ ́ i ~ h i ̀ n h ~ a ̉ n h ~ p l a n a r ~}$ trong lập kế hoạch điêu trị. Đối tượng và phương pháp: 52 bệnh nhân ung thư gan nguyên phát, giai đoạn trung gian và tiến triển được điêu trị tắc mạch xạ trị bằng hạt vi cầu gắn ${ }^{90}$ Y (TARE) được chọn vào nghiển cứu. Đặc điểm hình ảnh và các thông số lập kế hoach điều trị: shunt gan - phổi (LSF\%), chỉ số giữa khối u và gan lành ( $\mathrm{TNr}$ ) và liều hấp thụ của khối u (Dtumor) được thực hiên và đối chiếu trên ${ }^{99 \mathrm{~m} T \mathrm{~T}-\mathrm{MAA}}$ SPECT/CT và planar. Kết quả: Các đặc điểm hình ảnh cân đánh giá gồm: mật độ phân bố phóng xạ, hoại tử

*Bệnh viện TUQQĐ 108

Chiu trách nhiệm chính: Mai Hồng Sơn

Email: alex.hong.son@gmail.com

Ngày nhận bài: 17.12.2020

Ngày phản biện khoa họ: 21.01.2021

Ngày duyệt bài: 2.2.2021
Mai Hồng Sơn*, Nguyễn Bình An*, Lê Ngọc Hà*

và huyết khối được quan sát trên SPECT/CT tốt hơn so với planar. Tướng quan và đồng thuận của $\mathrm{TNr}$ trên SPECT/CT và planar ở mức trung bình, sự khác biệt có ý nghĩa thống kê $(P<0,05)$. Liêu chiếu khối u trển planar là 120 nhỏ hơn so với 155 trên SPECT/CT $(P<0,05)$. Kết luân: ${ }^{99 m T C-M A A ~ S P E C T / C T ~ p h a ́ t ~ h i e ̣ ̂ n ~}$ được đăc điểm hình ảnh khối $u$, huyết khối tĩnh mach cửa và ước tính liều điều trị cao hơn so với planar.

Tư khóa: Ung thư biểu mô tế bào gan, lập kê hoạch điều trị, tắc mạch xạ trị, hạt vi cầu gắn ${ }^{90} Y$, 99mic-MAA SPECT/CT, planar.

\section{SUMMARY}

\section{CHARACTERISTIC IMAGING OF 99M TC-MAA SPECT/CT IN PRE-TREATMENT PLANNING OF ${ }^{90} Y$ RESIN MICROSPHERES IN HEPATOCELLULAR CARCINOMA}

Background and aim: 99mTC-MAA SPECT/CT imaging is performed after radioembolization to reevaluate the resin microsphere distribution and estimate the absorbed radiation dose of target tumor. However, role of 99mTc-MAA SPECT/CT simulation was not well established until now. The purpose of our study is to validate the utility of SPECT/CT compared to planar simulation in dosimetry. Material and method: Fifty - two consecutive HCC patients, 